\title{
Prevalência de hipocalcemia em vacas leiteiras mestiças em função das composições genéticas, dos dias em lactação e da ordem de lactação
}

Rafahel Carvalho de Souza,'Rogério Carvalho Souza, Breno Mourão de Sousa, Rafael Rodrigues Brito, Bruno Machado Saturnino, Leandro Silva de Andrade, Fabricio Alves Rezende.

Pontifícia Universidade Católica de Minas (PUC Minas), Betim, MG, Brasil

*Autor correspondente

e-mail: rafahelsouza@pucminas.br

\section{Resumo}

Com o objetivo de avaliar a prevalência de corpos cetônicos em rebanhos de vacas mestiças Holandês $\mathrm{x}$ Gir, foi conduzindo procedimento experimental com 111 vacas em lactação, oriundas de oito sistemas semi-intensivos de produção de leite, localizados no estado de Minas Gerais. A produção média de leite das vacas era de 25,55 kg/dia, sendo de diferentes composições genéticas (entre 1/2 Holandês x Gir até 7/8 Holandês x Gir). Para mensuração da concentração sérica de cálcio, os animais foram submetidos à coleta de sangue por punção da artéria ou veia coccídea, utilizando para armazenagem tubo vacutainer sem anticoagulante de $5 \mathrm{ml}$. Posteriormente, foram centrifugados a $5000 \mathrm{rpm}$ durante 5 minutos (centrífuga Fanen ${ }^{\circledR}$ ), congelando o soro sobrenadante a $-20^{\circ} \mathrm{C}$ em tubos Eppendorf , e encaminhados ao Laboratório de Patologia Clínica da Escola de Veterinária da PUC Minas em Betim/MG. A dosagem laboratorial de cálcio foi feita com utilização do kit Bioclin ${ }^{\circledR}$ Cálcio Arsenazo III (Quibasa Química Básica LTDA, Belo HorizonteMG-Brasil), por meio de espectofotometria, utilizando o aparelho Bioclin 100. Para todos os efeitos, foi considerado animal clinicamente normal com concentração de cálcio igual ou maior que $8,6 \mathrm{mg} / \mathrm{dL}$. Qualquer valor abaixo desta referência foi considerado quadro de hipocalcemia, sendo subclínica quando a concentração estivesse entre 5,6 a 8,5 mg/dL e clínica para concentrações de cálcio menores que 5,5 $\mathrm{mg} / \mathrm{dL}$. Os resultados experimentais de prevalência simples - Prevalência (\%) = [número de observações da variável estudada/ número de observações totais] x 100 - foram agrupados segundo a composição genética dos animais $(1 / 2 ; 3 / 4 ; 5 / 8$; e $7 / 8$ Holandês x Gir), dias em lactação ( 0 a 7 ; 8 a $14 ; 15$ a 21; e 22 a 28 dias) e ordem de lactação (primípara e multípara). Nas 111 vacas experimentais não foi observada hipocalcemia clínica (concentração de cálcio menor que 5,5 mg/dL). Entretanto, foi observada taxa geral de prevalência para hipocalcemia subclínica em $28,8 \%$ das vacas estudadas (32/111), onde a concentração de cálcio foi entre 5,6 a $8,5 \mathrm{mg} / \mathrm{dL}$. As remanescentes $71,2 \%$ vacas $(79 / 111)$ foram consideradas normais 
(concentração de cálcio superior a 8,6 mg/dL). Discriminando as variáveis estudadas, a prevalência de hipocalcemia subclínica segundo a composição genética das vacas em lactação foi: vacas $1 / 2$ Holandês $\mathrm{x}$ Gir com 31,0\%, vacas 5/8 Holandês x Gir com 28,6\%, vacas 3/4 Holandês x Gir com 31,3\% e vacas 7/8 Holandês x Gir com 16,7\%. Para os dias em lactação, as prevalências foram de 28,0\% (0-7 dias), 27,6\% (8-14 dias), 29,2\% (15-21 dias) e 30,3\% (22 a 28 dias). Segundo a ordem de lactação, a hipocalcemia subclínica apresentou prevalência de 22,2\% para primíparas e 41,0\% para multíparas. A hipocalcemia subclínica em rebanhos de vacas mestiças Holandês x Gir foi alta em todos os estratos avaliados, sendo sua prevalência maior em multíparas. 